\title{
Melanoma in pregnancy
}

\begin{abstract}
Melanoma is one of the most common cancers diagnosed in pregnancy and has a high metastatic potential. As the incidence of melanoma increases, careful clinical evaluation of suspicious skin lesions remains the mainstay of early diagnosis. There is controversy in the literature as to whether pregnancyassociated melanoma has worse survival than other melanomas. Any changing-pigmented lesion should be biopsied, regardless of pregnancy hyperpigmentation. Increased lymphangiogenesis in pregnancy is associated with increased metastasis - timely diagnosis is therefore imperative. While the effect of oestrogen and progesterone on melanoma is under investigation, it is generally accepted that oral contraceptive use in not contraindicated after a diagnosis of melanoma in pregnancy. Subsequent pregnancy should be delayed for two to three years after a diagnosis of melanoma with a high risk of recurrence.
\end{abstract}

\section{Keywords \\ Pregnancy, melanoma, malignancy}

Date received: 27 April 2016; accepted: 16 January 2017

\section{Introduction}

The incidence of melanoma is increasing globally. ${ }^{1-3}$ It is estimated that one-third of all women diagnosed with melanoma are of childbearing age. ${ }^{4,5}$ With a trend towards delayed childbearing, there is a concern that pregnancy-associated melanoma will continue to increase. ${ }^{1}$ While metastatic melanoma carries a poor prognosis, the cutaneous nature of the disease means that it has the potential to be diagnosed early. However, patient self-examination and reporting are usually the pathway to further assessment by the clinician. ${ }^{6}$ The effect of pregnancy on melanoma is not well understood and continues to be debated. ${ }^{7}$ Producing clinical guidelines for the management of melanoma in pregnancy is therefore problematic. ${ }^{7}$ The management of metastatic melanoma is challenging and requires multidisciplinary care, which is individualised for each case. ${ }^{8}$ This article aims to raise awareness of melanoma in pregnancy and highlight the importance of early diagnosis. It will review the current hypothesised mechanisms for the effect of pregnancy on melanoma and discuss key aspects relevant to clinical practice.

\section{Epidemiology}

Melanoma represents a significant public health burden. The incidence varies around the world. In Australia, melanoma is the third most common cancer in women, after bowel and breast, accounting for $9 \%$ of all cancers in $2011 .{ }^{9}$ The incidence in 2011 was reported as 39 cases per 100,000 women. This is compared to an incidence of 15.9 per 100,000 women in the USA $(2008-2012) .{ }^{10}$ In the USA, the incidence of melanoma varies depending on the ethnicity with nonHispanic Caucasian people being most affected and non-Hispanic Afro-American being least affected. ${ }^{10}$ The incidence and mortality of melanoma have continued to increase over the last 40 years despite increased awareness and advances in management. ${ }^{3}$

The incidence of pregnancy-associated cancer is accepted to be 1 in 1000 pregnancies and is rising. ${ }^{1}$ Melanoma is one of the most commonly diagnosed cancers in pregnancy, and data suggest that $35 \%$ of women diagnosed with melanoma are of childbearing age (Table 1). ${ }^{11}$ Australian studies have reported the incidence of melanoma in pregnancy to be 45 per 100,000 maternities. ${ }^{1,12}$ This is higher than expected when compared to the general female population aged 15-44 years. ${ }^{1}$ The impact of pregnancy-associated melanoma on maternal morbidity and mortality will have increasing significance as the incidence rises with delayed childbearing (Table 1). ${ }^{12}$

\section{Pathology}

Melanoma is an aggressive form of skin cancer. Once the lesion has expanded beyond the boundary of the basement membrane and invades the dermis, it has the potential to metastasise. ${ }^{13}$ Tumour thickness, as measured by Breslow thickness, ${ }^{14,15}$ is an indicator of poorer prognosis as thicker tumours have increased risk of metastasis to the regional lymph nodes. ${ }^{13}$ Prognosis is based on the TNM staging system developed by the American Joint Committee on Cancer (Table 2). ${ }^{14}$ This system describes four stages of melanoma based on the primary tumour, regional lymph node and metastasis classifications. Thickness $>1 \mathrm{~mm}$, presence of ulceration and/or mitosis, and metastases are associated with worse prognosis. A useful tool for primary care physicians when evaluating pigmented lesions as potential melanomas is the ABCDE mneumonic; Asymmetry, Border, Colour, Diameter, Evolving (Table 2). ${ }^{15}$

\section{Mortality}

The diagnosis of melanoma in pregnancy is a relatively uncommon occurrence and most of the data are based on cohort studies, case reports and population studies. Study outcomes vary greatly. At present, there is no conclusive evidence to suggest that pregnancy-associated melanomas have a poorer prognosis than other melanomas. ${ }^{8}$ Case reports in the 1970s suggested that melanoma diagnosed in pregnancy was associated with worse outcomes. ${ }^{16-19}$ In contrast to the early case reports, more recent large-scale studies have reported that outcomes including survival in pregnant women with melanoma are not worse than in non-pregnant women. ${ }^{20-26}$ However, a recent meta-analysis reported that melanomas diagnosed during pregnancy or within 12 months postpartum do appear to have poorer outcomes. ${ }^{27}$ The authors have noted that the meta-analysis was limited by the varying

\footnotetext{
'Monash Health, Victoria, Australia

${ }^{2}$ Department of Maternal-Fetal Medicine, Royal Women's Hospital, Victoria, Australia

${ }^{3}$ Department of Obstetrics and Gynaecology, University of Melbourne, Victoria, Australia
}

\section{Corresponding author:}

Rebecca Still, Monash Health, 246 Clayton Road, Clayton, VIC 3168, Australia.

Email: rstill3@gmail.com 
Table I. Data from Lee et al.'

\begin{tabular}{ll}
\hline Cancer type & $\begin{array}{l}\text { Incidence per 100,000 } \\
\text { maternities }\end{array}$ \\
\hline Melanoma of the skin & 45.7 \\
Breast & 28.8 \\
Thyroid and other endocrine & 17.4 \\
Gynaecological & 14.3 \\
\hline
\end{tabular}

quality of the studies that have addressed the topic of prognosis of pregnancy-associated melanoma. ${ }^{27}$ Overall, the literature on this topic is confusing and contradictory. Further research is required to confidently ascertain whether pregnancy adversely affects melanoma prognosis. Further research into the plausible mechanisms for melanoma tumour progression in pregnancy, as discussed below, may be more appropriate and aid the clinician in diagnosis and management of affected pregnancies.

\section{Effect of pregnancy on melanoma}

There are various hypotheses regarding how pregnancy may affect melanoma progression. It is important to examine these hypotheses in detail to highlight certain characteristics of the disease, in the context of pregnancy, which may aid the clinician in diagnosis and management.

\section{Delayed diagnosis}

The hypothesis that pregnancy-associated melanoma may have worse outcomes than melanoma in non-pregnant women due to delayed diagnosis is plausible. It is widely accepted that pregnant women commonly experience increased skin pigmentation and specifically there are conflicting data about changes in pigmented naevi. ${ }^{27}$ Awareness of pregnancy-associated hyperpigmentation may distract the clinician from recognising a malignant change in a pre-existing pigmented naevi during pregnancy, which in turn may lead to a delay in diagnosis of melanoma. ${ }^{28-30}$ Two-thirds of melanomas occur in pre-existing naevi, and therefore any changing pigmented lesion should be biopsied. $^{4,12,13,24,31-33}$

\section{Lymphangiogenesis}

Lymphangiogenesis is increased in pregnancy. ${ }^{34}$ Studies have shown that the increased lymphangiogenesis associated with pregnancy leads to increased melanoma metastases. ${ }^{34,35}$ Increased lymphangiogenesis is the strongest independent predictor of melanoma sentinel node invasion. ${ }^{36}$ This is consistent with the known natural history of melanoma. ${ }^{13}$ The increased risk of lymphatic melanoma metastases in pregnancy highlights the importance of early diagnosis and where indicated, sentinel node biopsy.

\section{Pregnancy-associated plasma protein-A}

A recent study looking specifically at how pregnancy-associated plasma protein-A (PAPP-A) may affect melanoma progression has demonstrated a link between PAPP-A, melanoma and functional effects, mediated through insulin-like growth factor 1 (IGF1). ${ }^{37}$ The authors found that PAPP-A is highly expressed in human metastatic melanoma and prognosticates clinical outcome. ${ }^{37}$ They also demonstrated that silencing of PAPP-A blocks the motility of melanoma cells, and infer that PAPP-A can enhance melanoma cell migration by inducing IGF1 activity. ${ }^{37}$ These findings depict PAPP-A as a possible therapeutic target for pregnancy-associated melanoma and provide a plausible mechanism for accelerated melanoma progression during pregnancy.

\section{Tumour growth}

Some authors hypothesise that the growth factors associated with pregnancy may enhance tumour growth. ${ }^{12}$ Studies report increased Breslow thickness in pregnancy-associated melanomas when compared to other melanomas diagnosed in females of similar age. ${ }^{18,24,26,30}$ In addition, recent studies report that women who are diagnosed with melanoma in pregnancy are at increased risk of having a large-for-gestational age infant. ${ }^{1,12,34}$ Experiments on mice have demonstrated that melanomas grew more rapidly and had increased metastasis and mortality during gestation. ${ }^{34}$ These observations are the basis for the hypothesis that growth factors in pregnancy may enhance tumorigenesis. ${ }^{12}$ This highlights the importance of accurate tumour staging in pregnancy and surveillance of metastases. This also highlights that it is important to report on tumour thickness when conducting research on pregnancyassociated melanoma.

\section{Hormone effects}

Pregnancy is a state of increased circulating oestrogen and progesterone. The relationship between oestrogen and breast cancer has been widely studied and forms the basis of tamoxifen therapy. Tamoxifen is an anti-estrogenic agent that has been previously used to treat melanoma. It was found to inhibit tumour cell invasion in metastatic melanoma. ${ }^{38}$ However, treatment with tamoxifen is no longer recommended due to low response rates. ${ }^{39}$

Sex hormones are known to be associated with increases in melanocytes and melanin production. ${ }^{40}$ It is also well understood that oestrogen is implicated in the initiation of other cancers, but the effect of the sex hormones on melanoma progression is currently unclear. ${ }^{41}$ Recent research into the relationship between oestrogen and melanoma has focused on expression of oestrogen receptor $\beta$ (ER $\beta)$. ER $\beta$ expression decreases with increasing Breslow thickness of malignant melanomas. ${ }^{41}$ This suggests that reduced ER $\beta$ expression may be associated with tumours that have poorer prognosis. Therefore, ER $\beta$ expression could potentially be translated into a prognostic indicator. ${ }^{41,42}$ Reduced ER $\beta$ expression could account for the failure of treatment of melanoma with tamoxifen. ${ }^{42}$ In addition, oestrogen modulates the immune system and may influence tumour progression. ${ }^{43}$ Immune tolerance in pregnancy and its role in melanoma progression are discussed later.

There have been concerns regarding the increased risk of developing melanoma after using exogenous hormones in the form of oral contraceptives. However, recent data suggest that there is no difference in risk between women taking oral contraceptives compared to those who do not. ${ }^{4,41}$ Progesterone has not been as widely studied. In vitro studies have demonstrated that progesterone inhibits human melanoma cell growth by inducing autophagy, but this effect was not mediated via progesterone receptors. ${ }^{44}$ Melanocyte-stimulating hormone serum levels are raised in pregnancy ${ }^{40}$ but little research has been done on how this may affect melanoma in pregnancy.

Overall, there is potential for the development of prognostic indicators, but clarity regarding direct relationships between oestrogen, progesterone and melanoma await further research.

\section{Immune tolerance}

The immunogenicity of melanoma is well established and forms the basis of new therapies. It has been proposed that the mechanisms involved in maternal-fetal immune tolerance may allow for enhanced 
Table 2. TNM staging system for melanoma, adapted from AJCC. ${ }^{14}$

\begin{tabular}{|c|c|c|c|c|c|}
\hline $\begin{array}{l}\text { Primary } \\
\text { tumour }(\mathrm{T})\end{array}$ & Thickness & Subcategories & $\begin{array}{l}\text { Regional lymph } \\
\text { nodes (N) }\end{array}$ & $\begin{array}{l}\text { Number of } \\
\text { metastatic } \\
\text { nodes }\end{array}$ & Subcategories \\
\hline$T x$ & $\begin{array}{l}\text { Primary tumour } \\
\text { cannot be assessed }\end{array}$ & & $\mathrm{Nx}$ & $\begin{array}{l}\text { Patients in } \\
\text { which the } \\
\text { regional lymph } \\
\text { nodes cannot } \\
\text { be assessed. }\end{array}$ & \\
\hline T0 & $\begin{array}{l}\text { No evidence of } \\
\text { primary tumour }\end{array}$ & & No & $\begin{array}{l}\text { No regional } \\
\text { metastases } \\
\text { detected }\end{array}$ & \\
\hline \multirow[t]{2}{*}{ Tis } & \multirow[t]{2}{*}{ Melanoma in situ } & & \multirow[t]{2}{*}{$\mathrm{NI}$} & \multirow[t]{2}{*}{ I Node } & a: micrometastasis \\
\hline & & & & & b: macrometastasis \\
\hline \multirow[t]{2}{*}{ TI } & \multirow[t]{2}{*}{$\begin{array}{l}\text { Melanomas I.0 } \\
\text { mm or less in } \\
\text { thickness }\end{array}$} & $\begin{array}{l}\text { a: w/o ulceration } \\
\text { and mitosis } \\
<1 / \mathrm{mm}^{2}\end{array}$ & \multirow[t]{2}{*}{$\mathrm{N} 2$} & \multirow[t]{2}{*}{ 2-3 Nodes } & a: micrometastasis \\
\hline & & $\begin{array}{l}\text { b: with } \\
\text { ulceration and } \\
\text { mitosis } \geq 1 \mathrm{~mm}^{2}\end{array}$ & & & b: macrometastasis \\
\hline \multirow[t]{4}{*}{ T2 } & \multirow{2}{*}{$\begin{array}{l}\text { Melanomas I.0I- } \\
2.0 \mathrm{~mm}\end{array}$} & a: w/o ulceration & \multirow[t]{2}{*}{ N3 } & \multirow{2}{*}{$\begin{array}{l}4 \text { or more } \\
\text { nodes, or } \\
\text { matted nodes }\end{array}$} & a: micrometastasis \\
\hline & & $\begin{array}{l}\text { b: with } \\
\text { ulceration }\end{array}$ & & & b: macrometastasis \\
\hline & \multirow{2}{*}{$\begin{array}{l}\text { Melanomas 2.0I- } \\
4.0 \mathrm{~mm}\end{array}$} & a: w/o ulceration & & & \\
\hline & & $\begin{array}{l}\text { b: with } \\
\text { ulceration }\end{array}$ & & & \\
\hline \multirow[t]{2}{*}{ T4 } & \multirow{2}{*}{$\begin{array}{l}\text { Melanomas more } \\
\text { than } 4.0 \mathrm{~mm}\end{array}$} & a: w/o ulceration & & & \\
\hline & & $\begin{array}{l}\text { b: with } \\
\text { ulceration }\end{array}$ & & & \\
\hline
\end{tabular}

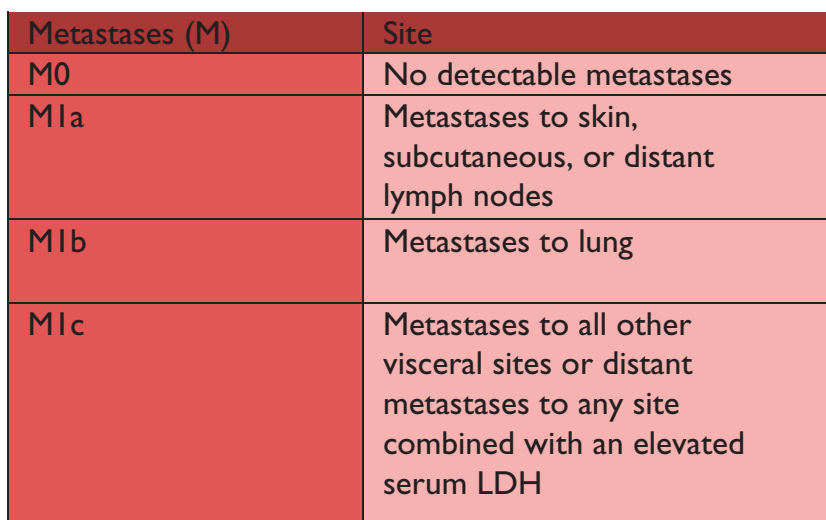

\begin{tabular}{|l|l|}
\hline \multirow{2}{*}{ Stage 0 } & Tis, N0, M0 \\
\hline Stage IA & TIa, N0, M0 \\
\hline \multirow{2}{*}{ Stage IB } & TIb, NO, M0 \\
\cline { 2 - 2 } & T2a, N0, M0 \\
\hline \multirow{2}{*}{ Stage 2A } & T2b, NO, M0 \\
\cline { 2 - 2 } & T3a, N0, M0 \\
\hline \multirow{2}{*}{ Stage 2B } & T3b, N0, M0 \\
\cline { 2 - 2 } & T4a, N0, M0 \\
\hline Stage 2C & T4b, N0, M0 \\
\hline Stage 3 & Any T, $\geq N I$, MO \\
\hline Stage 4 & Any T, Any N, MI \\
\hline
\end{tabular}

Note: Pathologic staging is performed, in addition to clinical staging, after lymphadenectomy. AJCC: American Joint Committee on Cancer; LDH: lactate dehydrogenase.

tumorigenesis of cancer during pregnancy. ${ }^{27}$ Indolamine 2,3 dioxygenase (IDO) is an enzyme in the body that is currently being studied with regard to its paradoxical role in the mammalian immune system - in both fighting infections and immune tolerance. ${ }^{45}$

IDO is expressed in the placenta. ${ }^{46}$ In vitro, its function in the placental tissue is implicated in the inhibition of $\mathrm{T}$ lymphocyte proliferation. ${ }^{47,48}$ In addition, the presence of IDO in the lymph nodes draining a melanoma correlated with a poorer clinical outcome in comparison to patients with IDO negative lymph nodes. ${ }^{49}$ It is therefore possible that variations in IDO expression, and the influence of
IDO on cellular immunity in pregnancy, could affect melanoma progression potentially leading to a poorer prognosis. Further investigation into the role of IDO in melanoma growth and metastasis and pregnancy may provide further insight into the long debated subject of the effect of pregnancy on melanoma progression and mortality.

Oestrogen is also implicated in modulating immunity. The processes by which it may influence melanoma progression are varied and have been shown to both promote and hinder melanoma growth. ${ }^{43}$ Monitoring ER expression could help clinicians determine patient prognosis. ${ }^{43,41}$ 


\section{Effect of melanoma on pregnancy}

A recent population study reported no increased risk of preterm birth, planned birth, caesarean section or stillbirth with a diagnosis of melanoma in pregnancy. ${ }^{12}$ This is in contrast to adverse pregnancy outcomes reported for women diagnosed with cancers in general. ${ }^{1}$

Melanoma metastasis to the placenta and fetus is an important consideration. Malignant melanoma is the tumour that most frequently metastasises to the placenta and fetus, representing $30 \%$ of placental metastases. ${ }^{31,50-52}$ However, it is still an extremely rare event. In most cases, pregnancies that involve melanoma metastases to the placenta result in healthy, unaffected infants. ${ }^{53}$ However, affected infants carried a very poor prognosis ${ }^{53}$ and it can lead to intra-uterine fetal death. ${ }^{51}$ As there is minimal clinical data on placental metastases, it is difficult to provide recommendations. In general, women with melanoma in pregnancy should be counselled regarding this possibility, the placenta should be sent for histologic evaluation, and examination of the newborn should be performed. ${ }^{50}$

Data on fetal growth in pregnancies complicated by melanoma are limited. Studies have observed significantly increased rates of large for gestational age infants born to mothers with a diagnosis of melanoma in pregnancy. ${ }^{1,12}$ This may suggest that growth factors, or oncofetal antigens, involved in gestation may also be implicated in tumour growth during pregnancy. A potential mechanism for this observation is via IGF-2 mRNA-binding protein 3 (IMP-3), which is a protein that is expressed in human fetal tissues and appears to have an important role during embryogenesis. ${ }^{54}$ While it is undetectable in human adult tissues, increased levels have been detected in many cancers, including malignant melanoma. ${ }^{54}$ It has also been noted that the expression of IMP-3 in metastatic melanomas is significantly more than in thin melanomas. ${ }^{54}$ It is possible, that if a melanoma tumour present in the mother during pregnancy was secreting IMP-3, this may affect fetal growth, resulting in a large for gestational age fetus. This represents a topic of further research that may enhance our understanding of the relationship between melanoma and pregnancy. There is currently no literature addressing this theory.

An individualised approach is recommended when determining the timing of delivery. Careful consideration of gestation, cancer staging, parity, maternal age and fertility status is required. However, delivery at term should be targeted where possible. ${ }^{7}$ Termination of pregnancy does not result in spontaneous regression of melanoma. ${ }^{28,31}$ Early delivery may be considered in those patients with poorer prognosis to allow for more aggressive treatment. ${ }^{55}$ Examination of the newborn and placental histopathological examination postpartum is recommended. ${ }^{7}$

\section{Management of melanoma in pregnancy}

The management of cancer in pregnancy is complex and requires a multidisciplinary approach. ${ }^{8}$ Evidence-based treatment of metastatic melanoma in pregnancy is challenging due to the lack of high-level evidence. ${ }^{7}$ Treatment of primary disease is not different for the pregnant patient. ${ }^{8}$ Excisional biopsy allows for histopathologic analysis and prognostication, and is potentially curative. This is a fundamental step in gaining information to guide management of the disease in context of pregnancy.

After initial tumour staging on histopathology, subsequent wide local excision and lymph node assessment may be indicated. Wide local excision can be performed safely under local anaesthetic in all trimesters of pregnancy and generally should not be delayed until the postpartum period as it is potentially curative. ${ }^{8,53}$

Sentinel lymph node (SLN) mapping and biopsy using technetium during pregnancy is considered safe. ${ }^{8}$ Regarding the fetus, radiation doses $<100$ milli-grays ( $m G y$ ) do not increase incidence of malformation. ${ }^{50}$ The use of technetium during pregnancy poses minimal risk to the fetus, delivering a radiation dose of $<5 \mathrm{mGy} .{ }^{50}$ Therefore, concern for the fetus in this regard should not impact the decision to perform SLN mapping and biopsy during a pregnancy. The use of patent blue dye is not recommended due to the $1 \%$ risk of an allergic reaction. ${ }^{8}$ Lymphadenectomy during pregnancy is challenging as it requires general anaesthesia, which poses a risk to the developing fetus. ${ }^{53}$ As lymphadenectomy is semi-elective, generally it is advised to wait until the postpartum period. ${ }^{53}$ In support of this advice, studies have shown that the delay of SLN biopsy is unlikely to have a substantial impact on survival. ${ }^{56}$ However, as noted previously in this article, pregnancy involves enhanced lymphangiogenesis, which is associated with increased melanoma metastasis. ${ }^{34,35}$ This may be an argument in favour of timely SLN biopsy and lymphadenectomy. After careful consideration of risk-benefit, if further surgery is indicated, second trimester is the safest in which to perform surgery where possible. ${ }^{57}$ Recently, successful videoscopic inguinal lymphadenectomy on a pregnant woman in the setting of malignant melanoma was described. ${ }^{58}$

Once surgical interventions and pathological staging are complete, systemic therapy may be indicated for unresectable melanomas. New systemic drugs are now available for the treatment of metastatic melanoma. However, their effect on pregnancy, lactation and fertility is largely unknown. One case report describes the successful use of vemurafenib in a pregnant woman during the second trimester, enabling prolonged gestation. ${ }^{59}$ Fetal monitoring during the period of administration identified that the pre-existing growth restriction of the fetus intensified. Delivery was performed by caesarean section and the child is healthy, but the mother died 2.5 months later. ${ }^{55}$ The use of vemurafenib in general is challenging with a $50 \%$ response rate but almost $100 \%$ rate of secondary resistance; therefore, drug combinations are required to improve survival rates. ${ }^{60}$ Animal studies have shown that vemurafenib does cross the placenta, but without any associated teratogenic effects. ${ }^{55}$ Lactation and contraception have not been studied, but it is worth noting that due to CYP3A4-mediated metabolism, the effect of hormonal contraceptives may be reduced in women taking vemurafenib.

Dabrafenib is a known teratogen and therefore contraindicated in pregnancy, and women of childbearing age must use effective contraception. ${ }^{55}$ However, debrafenib may also reduce effectiveness of hormonal contraceptives. ${ }^{55}$ Ipilimumab is associated with increased risk of miscarriage, stillbirth and pre-term birth, and therefore use in pregnancy should only be considered after rigorous risk-benefit assessment and consultation with the parents. ${ }^{55}$ Imatinib has been shown to be teratogenic resulting in minor malformations, such as clinodactyly and hypospadias, and an increased rate of miscarriage. ${ }^{55}$ Therefore, it should only be used if absolutely necessary with appropriate counselling. ${ }^{55}$

Conventional dermatooncologic drugs such as dacarbazine, interferon alpha, cyclophosphamide and bexarotene are all contraindicated in pregnancy. ${ }^{55}$

Recommendations for subsequent pregnancy after a diagnosis of melanoma are not standardised. ${ }^{4,50}$ The risk of recurrence is an important consideration when advising women on subsequent pregnancy. It is reasonable that those women with an early, thin melanoma not be restricted regarding future pregnancies. ${ }^{61}$ Those women with high risk of recurrence should delay pregnancy for two to three years. ${ }^{61}$ Current practice appears to be in line with this recommendation, as it was recently reported that the median time to subsequent birth in women diagnosed with melanoma in pregnancy was 2.64 years, which is similar to the 2.43 years in those women without melanoma. ${ }^{12}$ Advice should be based on risk and individual circumstance, considering prognosis, age, fertility status and family support. ${ }^{12,4,50}$

Breastfeeding may be interrupted during diagnosis, staging and treatment of melanoma. However, a diagnosis of melanoma in itself should not discourage breastfeeding. If systemic treatment is being used, breastfeeding should be avoided as some drugs have been shown to be excreted into breast milk, with unknown effects on the nursing infant.

The use of hormonal contraceptives and HRT is safe in women with a history of melanoma. ${ }^{41}$ The use of systemic therapy in the non-pregnant patient warrants effective contraception, as some drugs are known teratogens. ${ }^{55}$ However, these drugs may reduce efficacy of 
some hormonal contraceptives. ${ }^{55}$ In this context, the authors would recommend an intra-uterine contraceptive device.

Screening for melanoma in the form of whole-body skin checks is an important consideration. There is currently insufficient evidence to support whole-body skin checks for reducing melanoma mortality. ${ }^{8}$ Current guidelines suggest that population-based skin screening costeffectiveness is comparable to that of other screening modalities, and most cost-effective when conducted in those over 50 years. ${ }^{8}$ However, the current standard in general practice remains as patient self-examination and opportunistic screening. ${ }^{6}$ As the incidence of melanoma in women of child-bearing age is pronounced, the antenatal consultation represents an important opportunity to discuss melanoma concerns with the patient and facilitate early diagnosis.

\section{Conclusion}

The incidence of cancer in pregnancy is increasing. This is largely associated with contemporary trends towards delayed childbearing and therefore an older maternity population. Clinicians should be aware of melanoma as a significant contributor to maternal morbidity and mortality. Any changing pigmented lesion in pregnancy should be biopsied. Further research is required to guide evidence-based treatment and improve outcomes of melanoma in pregnancy. While treatment of primary disease in the pregnant patient is straightforward, metastatic melanoma requires multidisciplinary care in a tertiary centre. Clinicians must be proficient in providing timely diagnosis and management, where possible, for all cancers in pregnancy.

\section{Declaration of conflicting interests}

The author(s) declared no potential conflicts of interest with respect to the research, authorship, and/or publication of this article.

\section{Funding}

The author(s) received no financial support for the research, authorship, and/or publication of this article.

\section{Ethical approval}

Not applicable.

\section{Guarantor}

RS.

\section{Contributorship}

All authors contributed to the manuscript development and approved the final version of the manuscript for submission.

\section{References}

1. Lee YY, Roberts CL, Dobbins T, et al. Incidence and outcomes of pregnancy-associated cancer in Australia, 1994-2008: a populationbased linkage study. BJOG 2012; 119: 1572-1582.

2. Olesen AV, Parner ET, Mortensen PB, et al. Prenatal risk factors for cutaneous malignant melanoma: follow-up of 2,594,783 Danes Born from 1950 to 2002. Cancer Epidemiol Biomarkers Prev 2009; 18: $155-161$.

3. Lowe GC, Saavedra A, Reed KB, et al. Increasing incidence of melanoma among middle-aged adults: an epidemiologic study in Olmsted County, Minnesota. Mayo Clin Proc 2014; 89: 52-59.

4. Jhaveri MB, Driscoll MS and Grant-Kels JM. Melanoma in pregnancy. Clin Obstet Gynecol 2011; 54: 537-545.

5. Lens $\mathrm{M}$ and Bataille V. Melanoma in relation to reproductive and hormonal factors in women: current review on controversial issues. Cancer Causes Control 2008; 19: 437-442.
6. Sinclair R. Skin checks. Aust Fam Physician 2012; 41: 464-469.

7. Peccatori FA, Azim HA, Orecchia R, et al. Cancer, pregnancy and fertility: ESMO Clinical Practice Guidelines for diagnosis, treatment and follow-up. Ann Oncol 2013; 24(Suppl 6): vi160-vi170.

8. Australian Cancer Network Melanoma Guidelines Revision Working Party. Clinical Practice Guidelines for the Management of Melanoma in Australia and New Zealand. Cancer Council Australia and Australian Cancer Network, Sydney and New Zealand Guidelines Group, Wellington, 2008, www.cancer. org.au/health-professionals/clinical-guidelines/skin-cancer.html (accessed 15 February 2016).

9. Melanoma Institute Australia. Melanoma Facts and Statistics, www.melanoma.org.au/understanding-melanoma/melanomafacts-and-statistics/ (accessed 27 February 2016).

10. U.S. Cancer Statistics Working Group. United States Cancer Statistics: 1999-2011 incidence and mortality web-based report. Atlanta: U.S. Department of Health and Human Services, Centers for Disease Control and Prevention and National Cancer Institute, www.cdc.gov/uscs (2014, accessed 5 April 2015).

11. Teplitzky S, Sabates B, Yu K, et al. Melanoma during pregnancy: a case report and review of the literature. J La State Med Soc 1998; 150: 539-543.

12. Bannister-Tyrrell M, Roberts CL, Hasovits $C$, et al. Incidence and outcomes of pregnancy-associated melanoma in New South Wales 1994-2008. Aust N Z J Obstet Gynaecol 2015; 55: 116-122.

13. Liu V and Mihm MC. Pathology of malignant melanoma. Surg Clin North Am 2003; 83: 31-60, v.

14. Balch CM, Gershenwald JE, Soong S-J, et al. Final version of 2009 AJCC melanoma staging and classification. J Clin Oncol 2009; 27: 6199-6206.

15. Emery J. Melanoma - improving diagnosis in general practice. Aust Fam Physician 2011; 40: 991.

16. Pack GT and Scharnagel IM. The prognosis for malignant melanoma in the pregnant woman. Cancer 1951; 4: 324-334.

17. Byrd BF and McGanity WJ. The effect of pregnancy on the clinical course of malignant melanoma. South Med J 1954; 47: 196-200.

18. Slingluff CL, Reintgen DS, Vollmer RT, et al. Malignant melanoma arising during pregnancy. A study of 100 patients. Ann Surg 1990; 211: 552-559.

19. Shiu MH, Schottenfeld D, Maclean B, et al. Adverse effect of pregnancy on melanoma: a reappraisal. Cancer 1976; 37: 181-187.

20. Lens M, Rosdahl I and Newton-Bishop J. Cutaneous melanoma during pregnancy: is the controversy over? J Clin Oncol 2009; 27 : e11-12; author reply e13-14.

21. Stensheim H, Møller B, van Dijk T, et al. Cause-specific survival for women diagnosed with cancer during pregnancy or lactation: a registry-based cohort study. J Clin Oncol 2009; 27: $45-51$.

22. O'Meara AT, Cress R, Xing G, et al. Malignant melanoma in pregnancy. A population-based evaluation. Cancer 2005; 103: $1217-1226$

23. McManamny DS, Moss ALH, Briggs JC, et al. Melanoma and pregnancy: a long-term follow-up. BJOG 1989; 96: 1419-1423.

24. Daryanani D, Plukker JT, De Hullu JA, et al. Pregnancy and early-stage melanoma. Cancer 2003; 97: 2248-2253.

25. Leachman SA, Jackson R, Eliason MJ, et al. Management of melanoma during pregnancy. Dermatol Nurs 2007; 19: 145-152, 161.

26. MacKie RM, Bufalino R, Morabito A, et al. Lack of effect of pregnancy on outcome of melanoma. Lancet 1991; 337: 653-655.

27. Byrom L, Olsen C, Knight L, et al. Increased mortality for pregnancy-associated melanoma: systematic review and meta-analysis. J Eur Acad Dermatol Venereol 2015; 29: 1457-1466.

28. Lishner M. Cancer in pregnancy. Ann Oncol 2003; 14(Suppl 3): iii31-iii36.

29. Errickson CV and Matus NR. Skin disorders of pregnancy. Am Fam Physician 1994; 49: 605-610. 
30. Travers RL, Sober AJ, Berwick M, et al. Increased thickness of pregnancy-associated melanoma. Br J Dermatol 1995; 132: 876-883.

31. Dillman RO, Vandermolen LA, Barth NM, et al. Malignant melanoma and pregnancy ten questions. West J Med 1996; 164: $156-161$.

32. Driscoll MS and Grant-Kels JM. Hormones, nevi, and melanoma: an approach to the patient. J Am Acad Dermatol 2007; 57: 919-936.

33. Mestnik NC, Afonso JPJM, Enokihara MMSeS, et al. Melanoma developed during pregnancy - a case report. An Bras Dermatol 2014; 89: 157-159.

34. Khosrotehrani K, Nguyen Huu S, Prignon A, et al. Pregnancy promotes melanoma metastasis through enhanced lymphangiogenesis. Am J Pathol 2011; 178: 1870-1880.

35. Rodero MP, Prignon A, Avril MF, et al. Increase lymphangiogenesis in melanoma during pregnancy: correlation with the prolactin signalling pathway. J Eur Acad Dermatol Venereol 2013; 27: e144-e145.

36. Dadras SS, Lange-Asschenfeldt B, Velasco P, et al. Tumor lymphangiogenesis predicts melanoma metastasis to sentinel lymph nodes. Mod Pathol 2005; 18: 1232-1242.

37. Prithviraj P, Anaka M, McKeown SJ, et al. Pregnancy associated plasma protein-A links pregnancy and melanoma progression by promoting cellular migration and invasion. Oncotarget 2015; 6: 15953-15965.

38. Matsuoka H, Tsubaki M, Yamazoe Y, et al. Tamoxifen inhibits tumor cell invasion and metastasis in mouse melanoma through suppression of PKC/MEK/ERK and PKC/PI3K/Akt pathways. Exp Cell Res 2009; 315: 2022-2032.

39. Lens MB, Reiman $T$ and Husain AF. Use of tamoxifen in the treatment of malignant melanoma. Cancer 2003; 98: 1355-1361.

40. Vora RV, Gupta R, Mehta MJ, et al. Pregnancy and skin. J Family Med Prim Care 2014; 3: 318-324.

41. de Giorgi V, Gori A, Grazzini M, et al. Estrogens, estrogen receptors and melanoma. Expert Rev Anticancer Ther 2011; 11: 739-747.

42. Zhou JH, Kim KB, Myers JN, et al. Immunohistochemical expression of hormone receptors in melanoma of pregnant women, nonpregnant women, and men. Am J Dermatopathol 2014; 36: 74-79.

43. Enninga EAL, Holtan SG, Creedon DJ, et al. Immunomodulatory effects of sex hormones: requirements for pregnancy and relevance in melanoma. Mayo Clin Proc 2014; 89: 520-535.

44. Ramaraj $P$ and Cox JL. In vitro effect of progesterone on human melanoma (BLM) cell growth. Int J Clin Exp Med 2014; 7: 3941-3953.

45. Dürr S and Kindler V. Implication of indolamine 2,3 dioxygenase in the tolerance toward fetuses, tumors, and allografts. $J$ Leukoc Biol 2013; 93: 681-687.

46. Yamazaki F, Kuroiwa T, Takikawa O, et al. Human indolylamine 2,3-dioxygenase. Its tissue distribution, and characterization of the placental enzyme. Biochem $J$ 1985; 230: 635-638.
47. Culouscou JM, Remacle-Bonnet MM, Pommier G, et al. Immunosuppressive properties of human placenta: study of supernatants from short-term syncytiotrophoblast cultures. $J$ Reprod Immunol 1986; 9: 33-47.

48. Clark DA, Slapsys R, Chaput A, et al. Immunoregulatory molecules of trophoblast and decidual suppressor cell origin at the maternofetal interface. Am J Reprod Immunol Microbiol 1986; 10: $100-104$.

49. Munn DH, Sharma MD, Hou D, et al. Expression of indoleamine 2,3-dioxygenase by plasmacytoid dendritic cells in tumor-draining lymph nodes. J Clin Invest 2004; 114: 280-290.

50. Schwartz JL, Mozurkewich EL and Johnson TM. Current management of patients with melanoma who are pregnant, want to get pregnant, or do not want to get pregnant. Cancer 2003; 97: 2130-2133.

51. Sebire NJ and Jauniaux E. Fetal and placental malignancies: prenatal diagnosis and management. Ultrasound Obstet Gynecol 2009; 33: $235-244$.

52. Altman JF, Lowe L, Redman B, et al. Placental metastasis of maternal melanoma. J Am Acad Dermatol 2003; 49: 1150-1154.

53. Broer N, Buonocore S, Goldberg C, et al. A proposal for the timing of management of patients with melanoma presenting during pregnancy. J Surg Oncol 2012; 106: 36-40.

54. Sheen Y-S, Liao Y-H, Lin M-H, et al. IMP-3 promotes migration and invasion of melanoma cells by modulating the expression of HMGA2 and predicts poor prognosis in melanoma. $J$ Invest Dermatol 2015; 135: 1065-1073.

55. Grunewald S and Jank A. New systemic agents in dermatology with respect to fertility, pregnancy, and lactation. JDDG 2015; 13 : 277-290.

56. Kirkwood JM, Ibrahim JG, Sondak VK, et al. High- and lowdose interferon alfa-2b in high-risk melanoma: first analysis of intergroup trial E1690/S9111/C9190. J Clin Oncol 2000; 18: 2444-2458.

57. Jenkins TM, Mackey SF, Benzoni EM, et al. Non-obstetric surgery during gestation: risk factors for lower birthweight. Aust N Z J Obstet Gynaecol 2003; 43: 27-31.

58. Davis JR, Trocha SD, Hale AL, et al. Videoscopic inguinal lymphadenectomy in malignant melanoma: safe in pregnancy? J Surg Case Rep 2014; Nov 5: pii: rju103. doi: 10.1093/jscr/rju103.

59. Maleka A, Enblad G, Sjörs G, et al. Treatment of metastatic malignant melanoma with vemurafenib during pregnancy. J Clin Oncol 2013; 31: e192-193.

60. Swaika A, Crozier JA and Joseph RW. Vemurafenib: an evidencebased review of its clinical utility in the treatment of metastatic melanoma. Drug Des Devel Ther 2014; 8: 775-787.

61. Driscoll MS and Grant-Kels JM. Nevi and melanoma in pregnancy. Dermatol Clin 2006; 24: 199-204, vi. 